\title{
Nature of Samuel Pepys's "wind colic"
}

\author{
CHARLES NEWMAN
}

The abdominal trouble that is most commonly referred to in Pepys's Diary is what he called "the wind colic." This is generally thought to have been renal colic because $(a)$ he was found at necropsy to have a nest of stones in his left kidney, (b) he passed stones after attacks of colic at least once, and (c) he had had the famous operation for stone in the bladder just before the start of the Diary. No details are known of the precise nature of the operation, and nothing has been published in the way of critical speculation about it. He was naturally in constant dread of a recurrence, and consequently paid great attention to pains in the lower abdomen. His pains were of several different kinds.

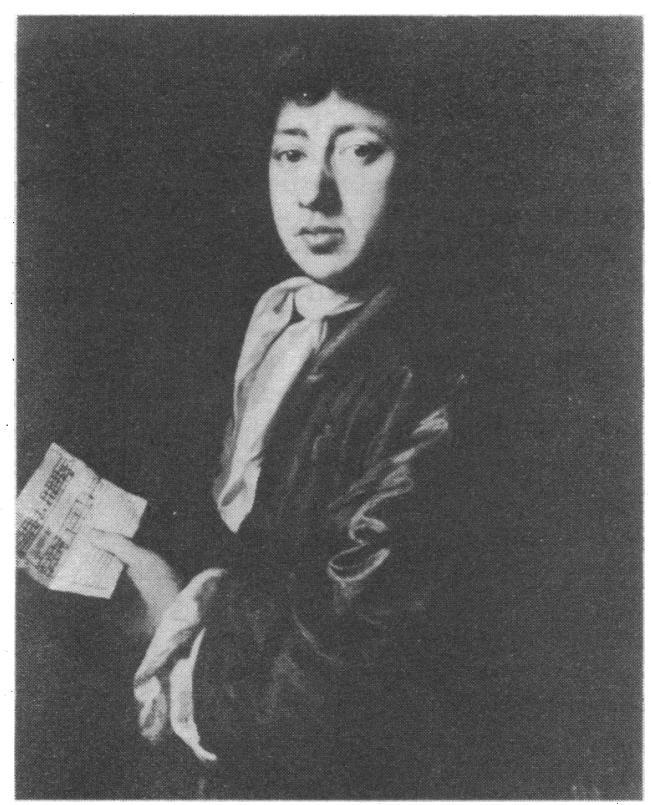

Pepys at the age of 33 with a copy of the manuscript of his song "Beauty Retire" in his hand. Painted by John Hayls in 1666. (Courtesy of the National Portrait Gallery.)

The first was genuine renal colic. He had an attack on 7 March 1665 , with pain radiating to the left testis, confirmed by passing two stones: and another possible one, unconfirmed, on 7-8 July 1666.

He also had attacks of pain and swelling of the testis, always, when he noted the side, the right one. There was definitely swelling on 10 and 18 October 1661, 5 and 6 February 1662, and 19 March 1664, but it was not noted on five other occasions. He thought it was caused by trauma or cold: trauma seems to have called attention to it rather than to have caused it ( 1 October 1661). Poulticing seemed to do it good, and it is said to have been epididymitis caused by results of the operation. In time the attacks faded: he had two in 1661, four in 1662, one in 1663, 1664, and 1665, two in 1666, and none in the next two years.

He also had attacks of pain on micturition and in the back,

Royal College of Physicians, London NW1 4LE

CHARLES NEWMAN, MD, FRCP, formerly Harveian Librarian sometimes with pus in the urine (1 July 1664) and fever. They were almost certainly cystitis, sometimes progressing to pyelonephritis. He had two attacks in 1660, one in 1661 and in 1662, a doubtful one in 1663, two in 1664 and in 1665, and none subsequently.

He had one attack of pain in the back "after straining last night to get open my plate chest" (12 December 1666). An orthopaedic surgeon in New Zealand suggested that all his pains were the sacroiliac syndrome, but Pepys did not think that this attack was like any of his others, and he had had all varieties of attack long before this episode.

Having separated these diagnosable disorders, there remains the commonest of them: what he called "the wind colic." All the details were not available until the publication of the new complete text edited by Latham and Matthews. ${ }^{1}$ This includes the many harmless but vulgar lavatory words, without which the picture is misleading. For lack of information it has usually been supposed that it was renal colic, but Pepys himself, who had reason to know, usually thought it was not, but, thinking in terms of Galenical medicine, as everyone did at that time, concluded that the cause was "taking cold," in the sense of ingesting a lump of coldness, as it were. This had become an obsession with laymen and doctors alike. It might make the patient feel cold, or, by reacting to it, it might make him hotyou could have it either way. Remains of this belief survive to this day.

\section{Taking cold}

Pepys thought he "took cold":

(1) By getting his feet cold-for instance, 22 September 1662, 9 July 1663, and 26 May 1664.

(2) By putting his legs into water (14 June 1661 and 20 June 1666).

(3) By drinking cold water, milk, or weak alcoholic drinks (19 August and 17 November 1663, 7 June and 16 August 1667). Cold small beer was also blamed as the cause of his father's strangulated hernia (29 April 1663). He never blamed strong drink: he regarded it rather as curative.

(4) By leaving off, or putting on extra clothing (9 July 1663, 10 February, 28 May, 7 June, and 31 August 1664, 20 June and 19 September 1666).

(5) By just "getting cold"-"having taken some cold yesterday on the water" (3 March and 15 August 1663); "some cold I must have got by the sudden change of weather" (26 March 1663, 19 January 1665, and 16 August 1667). It was not that observation suggested to him that he had taken cold: the fact that he had colic meant that he had done so, even if he had no idea when or how (16 February 1662, 10 February, and 14 December 1664, 13 May 1665). Colic and cold were inseparably associated in his mind, though other disorders also might follow taking cold.

Pepys believed that taking cold acted by causing wind, either in his bowels or elsewhere, and that the wind rose to whatever part of the body was uppermost. He attributed Lord Sandwich's illness at Alicante, which was probably dysentery, to "wind got into the muscles of his right side" (14 August 1661). All this is hardly to be wondered at when the doctors themselves told him that "cold breeds wind" (14 August 1664). He was equally convinced that breaking wind was the essential preliminary to a cure. ${ }^{2}$

Those who remember the era of that once so common and fashionable illness the "mucous colitis" or "spastic colon" may 
well suspect that the wind colic was a variant of that curious abdominal neurosis. It was very common in the first quarter of this century, when it "became the fashionable complaint, displacing neuritis to a great extent." ${ }_{3}$ It was associated with anxiety and depression, commoner in women, or in busy, energetic men; with constipation, an irritable bladder, sometimes with mucus in the faeces or even the urine; and with severe griping pain, sometimes to the point of fainting. It was aggravated by purges, which were often abused. It is now absorbed into the irritable bowel syndrome. ${ }^{4}$ There is actually an increase in intracolic pressure: that is how the emotional upset manifests itself physically. Purges are now avoided, and the treatment is by dietary care, treatment of the psychiatric disorder, and the alleviation of symptoms.

Wind colic was not uncommon in the 1660s. Pepys, with his remarkable candour and insight, knew well that the attacks were associated with press of business, anxiety, irritation over the incompetence of his colleagues, and frustration (3-12 October 1663, 6 April, 27 May 1664, and 8 February 1669), and he noted with surprise the effect of carrying a hare's foot as a preventive: on 20 January $1665 \mathrm{Mr}$ Batten "showed me my mistake, that my hare's foot hath not a joint to it. . . . And it is a strange thing how fancy works, for I no sooner almost handled his foot but my belly began to be loose and break wind ... . and I became very well, and so continue." (See also 31 December 1664.)

He sometimes confused other troubles with the wind colicfor instance:

(1) With the abdominal and general discomfort associated with delayed or inadequate meals ( 7 July 1663, 4 March, 13 May, and 4 December 1665, 3 April 1668, and 8 February 1669). This is useful, because most of us have experienced these symptoms, and they therefore provide a yardstick to indicate how unpleasant the colic was.

(2) $\mathrm{He}$ called obvious attacks of gastroenteritis wind colic (15 and 16 July 1666).

(3) On one occasion- "My great fit of the Cholique" 4 to 13 October 1663-he had what started like an attack of cystitis which developed into the usual colic with constipation. At the time of his recovery his bowels were opened, simply because he was well again, but he as usual took the effect of recovery for the cause.

(4) He sometimes attributed the colic to a return of the stone. The apprehension was only natural; moreover, the surgeon, Mr Hollyer, was sometimes not sure.

The annual incidence of Pepys's attacks of colic was: none in 1660 , two in 1661, three in 1662, eight in 1663, nine in 1664 , seven in 1665, four in 1666, two in 1667, and none in 1668 or 1669. The Diary makes it obvious that whereas when it started he was a cheerful, casual, easy-going, careless young man, he started a great personal reformation at the end of 1661 , made solemn vows to avoid dissipation and to attend to business, took his vows more and more seriously, and worried over excuses for breaking them, had new troubles in May 1662, relapsed in his conduct in April 1663, and suffered a combination of domestic and professional worries at the same time. By the end of 1665 things were going much better, and despite plague and fire his personal life was easier and more settled. By 1669 all his enemies and rivals in the Navy Office were gone, and he was established and secure. Neurotic complaints are common in strong, vigorous, active young men-they are more full of fads and fancies than many would suspect, and neurotic symptoms may play an unexpectedly useful part in making the inner life tolerable.

\section{Possible lead poisoning}

It is notoriously risky to fly to neurotic explanations of complicated symptoms: it is so easy to make everything fit in with the diagnosis. But neurosis is very common, and in Pepys's case looks more likely to be the truth than other ingenious alternatives. But in 1979 two doctors in Belfast, D A D
Montgomery and R A Womersley, suggested in a discussion that the wind colic may have been chronic lead poisoning. This is a much more likely possibility. Chronic lead poisoning is the typical colic with constipation-"dry colic," and it used to be common. It was known in Pepys's time as colica pictonum, because the inhabitants of Poitou suffered from it, presumably as a result of drinking contaminated cider. That association was first described, as the explanation of Devonshire colic, by Sir George Baker, a Devonshire man who became President of the Royal College of Physicians. The association was not known to Pepys's doctors: it was not discovered until $1767 . .^{5}$ Lead poisoning was often derived from the lead dissolved from pipes by soft water, or even, for a time, by hard water, and it is notable that Pepys's symptoms did not begin until he had moved from Axe Yard in Westminster to the Navy Office residences in Seething Lane in 1660. Before he moved in, he put in hand a large scheme of domestic improvements, including a complete reformation of his kitchen. Domestic water was partly piped from the New River but for the most part came from wells under the houses. It is possible that Pepys had new lead pipes put in, and if so it is likely that for some years lead would dissolve into the water, but that in time a coating of lime would be deposited in the pipes, and contamination would cease. The reconstructions were carried out between July and December 1660 , and are described, not in the Diary, but in a Rawlinson manuscript in the Bodleian Library.

There is no evidence that Pepys suffered from any of the other symptoms of lead poisoning. Mrs Pepys did on one occasion have wind colic (possibly) on 19 September 1666, but she was certainly not often affected and this counts against the diagnosis because women are more susceptible than men. Only an estimation of the lead still remaining in Pepys's bones would settle the question, but this might be more idle curiosity than medical research.

\section{References}

${ }^{1}$ Latham R, Matthews W. The Diary of Samuel Pepys. 9 vols. London: G Bell, 1970-1976. (References are given by date, which has evidentia value, not by volume and page number.)

2 Bryant A. Samuel Pepys. Vol 2. The years of peril. London: Cambridge University Press, 1935:409-10. (Appendix: a MS of Pepys of 7 November 1677.)

${ }^{3}$ Osler W. Principles and practice of medicine. 8th ed. London: Appleton, 1912:551.

4 Price F. Practice of medicine. 12th ed. Oxford: Oxford University Press, 1978:634

5 Baker G. An essay concerning the endemical colic of Devonshire. London: J Hughs, 1767.

(Accepted 9 fune 1980)

ONE HUNDRED YEARS AGO Sir,-No one who passes through the streets of London can fail, especially in hot weather, to notice from time to time most unpleasant odours in localities where they might be least expected. I should say that these indescribable odours, which remind one more of the pig-tub than anything else, are particularly frequent in aristocratic quarters. Whether the agitation that attributes the offensive smells in London streets to the condition of the streets themselves is justified or not, I beg to draw the attention of your readers to the undoubted fact, that many of the vile odours complained of are due to the extreme carelessness of housekeepers in regard to their dust-bins, which are constantly made the receptacles of refuse that ought to be burnt by the cook, or be disposed of before it becomes a heap of reeking putrefaction. I think that the observer of London life will be able to confirm the remark, that wealth and education do not necessarily impart to ladies a knowledge of the condition of the basement of their house. The management of the dust-bin is an important item in the sanitary, or unsanitary, condition of houses and of the streets they adjoin.-I am yours, etc., E H SIEVERING. (British Medical fournal, 1880.) 


\section{ZANY LESSONS FOR ACADEMICS}

Making visual aids work for you

\section{Graphics}

(1) Making negative data look positive- "massaging the data."

(a) Data should be presented in such a way as to give one of the following graphs:
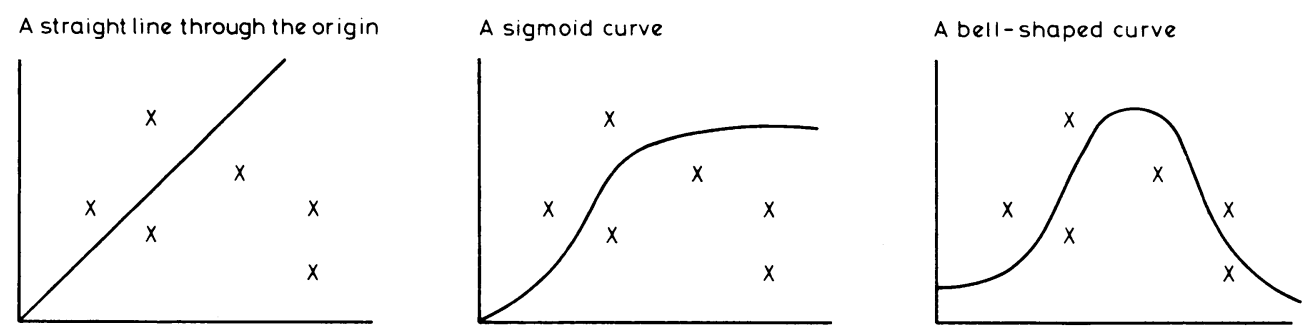

In biology it is good to have at least three (preferably all) of your data points not lying on the best fitting curve. Throw out points that do. This gives the reader the impression that you did not fudge the results or "dry lab" the experiment altogether.

In chemistry and physics it is probably wise to make all your data points fall on the curve. Throw out any that don't. Everyone knows that such results are the result of sloppy work and won't believe the good points that you show them.

(b) Give your graphs an experimental flavour by showing standard deviations. For example:

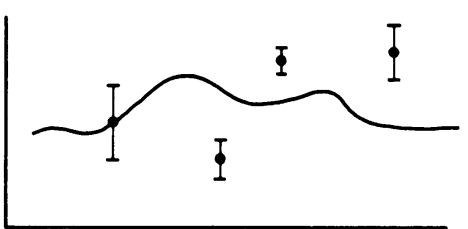

(c) Give your graphs appeal by having different coloured lines (not illustrated) or on a blue background.

(2) Making labels of graphs work for you (making mediocre data look like a breakthrough). We take the example of a randomised trial of malignant fungoma-a group of treated patients whose survival is compared to that in a randomised group of untreated controls. The uninspired author shows survival in years and obtains the following graph:

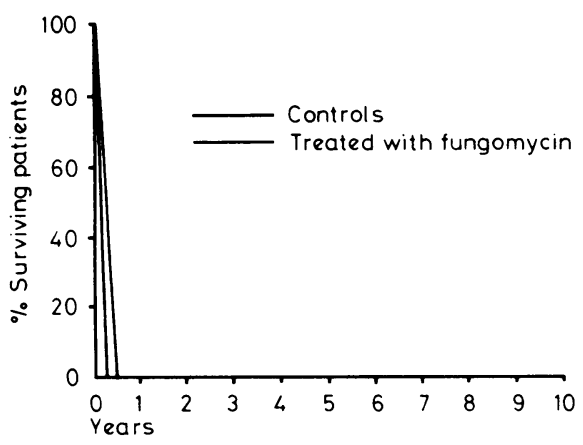

The moderately inspired investigator uses the same data points but depicts survival in weeks:

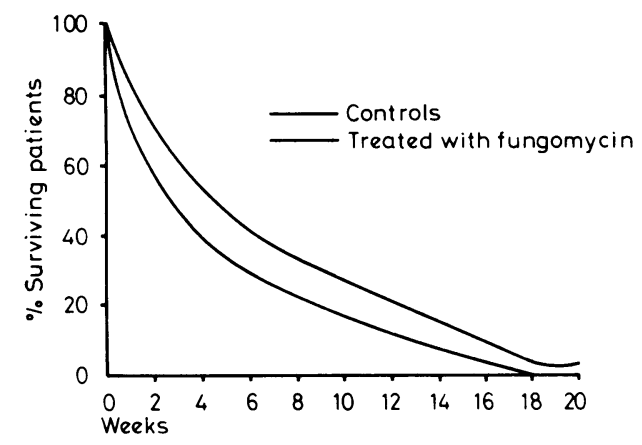

The breakthrough scientist, however, illustrates his survivals in seconds:

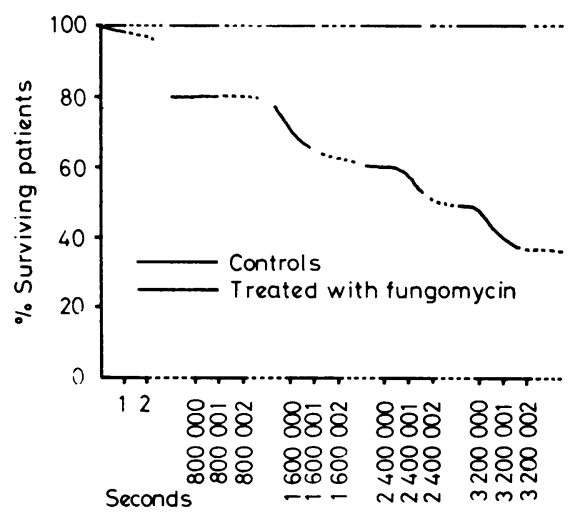

This illustration is accompanied by the statement, "The graph clearly shows that the median survival for treated patients was nine hundred thousand and fifteen seconds more than the untreated control group $(P<0.000000001)$."

(3) How to compare unrelated data-the use of the bar graph. For example:

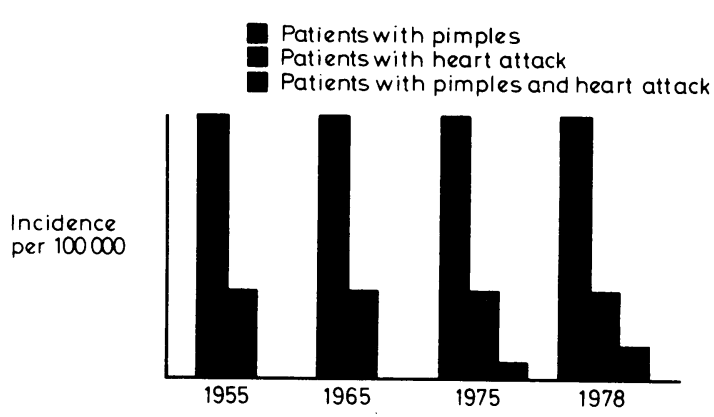

In the discussion, one should write the following interpretation: "Ever since our first case report in 1975 on the occurrence of coronary occlusion complicating pimples, we have observed an increased trend in this association. In our follow-up report of 50 additional cases in 1978 , there is a definite rise. Since this association has not yet been reported by other investigators, our graph almost certainly grossly undrestimeates the problem. If this trend continues-and with more reports-the risk of heart attack may approximate $100 \%$ of pimpled persons. The reason for this trend is not yet clear. We are considering environmental pollution and the possible release of cholesterol fats into the blood stream from the use of certain acne soap preparations. Until the epidemiology is worked out, physicians must follow all their patients with pimples closely for coronary occlusion and look for pimples in patients with signs and symptoms of heart attack."BERRIL YUSHOMERSKI YANKELOWITZ. 